\title{
A rare cause of neonatal hypertension: Congenital mesoblastic nephroma
}

\author{
Eren Soyaltın${ }^{1}$, Demet Alaygut ${ }^{1}$, Caner Alparslan ${ }^{1}$, Tunç Özdemir², Seçil Arslansoyu- \\ Çamlar ${ }^{1}$, Fatma Mutlubaş ${ }^{1}$, Belde Kasap-Demir ${ }^{1}$, Önder Yavaşcan ${ }^{1}$ \\ Departments of ${ }^{1}$ Pediatric Nephrology and ${ }^{2}$ Pediatric Surgery, Tepecik Training and Research Hospital, Izmir, Turkey. \\ E-mail: erensoyaltin@hotmail.com \\ Received: 27th March 2017, Revised: 14th June 2017, Accepted: 30th June 2017
}

\begin{abstract}
SUMMARY: Soyaltın E, Alaygut D, Alparslan C, Özdemir T, ArslansoyuÇamlar S, Mutlubaş F, Kasap-Demir B, Yavaşcan Ö. A rare cause of neonatal hypertension: Congenital mesoblastic nephroma. Turk J Pediatr 2018; 60: 198-200.

A rare cause of neonatal hypertension: Congenital Mesoblastic Nephroma (CMN) is a rare renal tumor in childhood and has been reported with palpable abdominal mass, hypertension, hematuria, polyuria and hypercalcemia. Histopathologically it has been classified into two histological types: classic and cellular. We present a 32-week gestation infant and his histopathology reports of cellular CMN presented with refractory hypertension.
\end{abstract}

Key words: hypertension, newborn, mesoblastic nephroma.

Congenital Mesoblastic Nephroma (CMN) is a rare renal tumor in childhood. It frequently presents within the first six months after birth and $80 \%$ of tumors occur in the neonatal period.1,2 Palpable abdominal mass, hypertension, hematuria, polyuria and hypercalcemia have been reported as clinical manifestations of CMN. ${ }^{3,4}$ The prognosis and the treatment plan are guided with clinical and morphological markers and type of tumor. ${ }^{4}$ Morphologically CMN has two histological types: classic and cellular. ${ }^{5}$ The cellular subtype has been reported to be more aggressive compared to classic subtype on the ground of its larger volume, cytological atypia, higher mitotic rate and increased cellularity. ${ }^{6}$ We report the clinical presentation and pathological reports of a 32 week gestation infant with cellular CMN presenting with refractory hypertension.

\section{Case Report}

A 2260 g male infant was born to a 26 -yearold woman after $32^{3 / 6}$ weeks gestation. In the second trimester, a renal mass was identified on the upper pole of the kidney by prenatal ultrasound. Corpus callosum agenesis and ventriculomegaly was detected simultaneously. The infant was delivered by cesarean section with Apgar scores of 1 and 5 at 1 and 5 minutes, respectively. Following cardiopulmonary resuscitation for five minutes the heart rate was $>100$ beats per minute. The infant was admitted to the pediatric surgical clinic of İzmir Tepecik Research Hospital. Due to lack of spontaneous breathing the patient was observed with the aid of a mechanical ventilator. The physical examination was significant for generalized edema and abdominal distention. The large mass was palpated on the left lower quadrant of the abdomen. The blood pressure was measured as $122 / 89$ $\mathrm{mmHg}$ (normal range 48 to $60 / 24$ to 38 ). Blood pressure measurements were found to be approximately $20-30 \mathrm{mmHg}$ higher in the upper limbs compared to the lower limbs. Urine output was normal.

Computerized tomography scan of the abdomen demonstrated the anterior and right side growing multiloculated, cystic-solid mass measuring $7.5 \times 7.5 \mathrm{~cm}$, originating from the left kidney, hydronephrosis in the right kidney and irregularly shaped large hypodense area in the right lobe of the liver.

The serum urea, creatinine and $\mathrm{CBC}$ were normal. Serum calcium was elevated to 13.6 $\mathrm{mg} / \mathrm{dl}$. Furosemide was started in addition to intravenous fluid administration for hypercalcemia. Escalating doses of furosemide and amlodipine were used for treatment of 
hypertension. During the treatment period the blood pressure was in the 95th percentile. On day 4 of life, laparotomy and left nephrectomy were performed. There was no metastatic disease in the peritoneum. The blood pressure normalized within a few hours after the surgery and the difference between lower and upper extremity blood pressures reduced. Treatment for hypertension were discontinued.

Histologically the tumor was characterized by fusiform and ovoid cells with high mitotic activity. The tumor cells were positive with vimentin and WT1. The pathology confirmed the tumor as cellular CMN. The infant has been following up in the neonatal unit for other neurological and gastrointestinal anomalies. Informed consent was received from the family.

\section{Discussion}

CMN has been reported as the most common renal tumor in infancy and first six months of life. ${ }^{2}$ The tumor is frequently detected by prenatal ultrasonography. ${ }^{7}$ The most common clinical presentation is asymptomatic abdominal mass. ${ }^{1,8}$ The clinical paraneoplastic syndromes especially hypercalcemia and hypertension have been reported in infants with CMN.8,9 Other presenting symptoms have been described as hematuria and polyuria.

Bayindir et al. determined that $70 \%$ of patients with CMN presented with refractory hypertension. ${ }^{1}$ The underlying mechanism

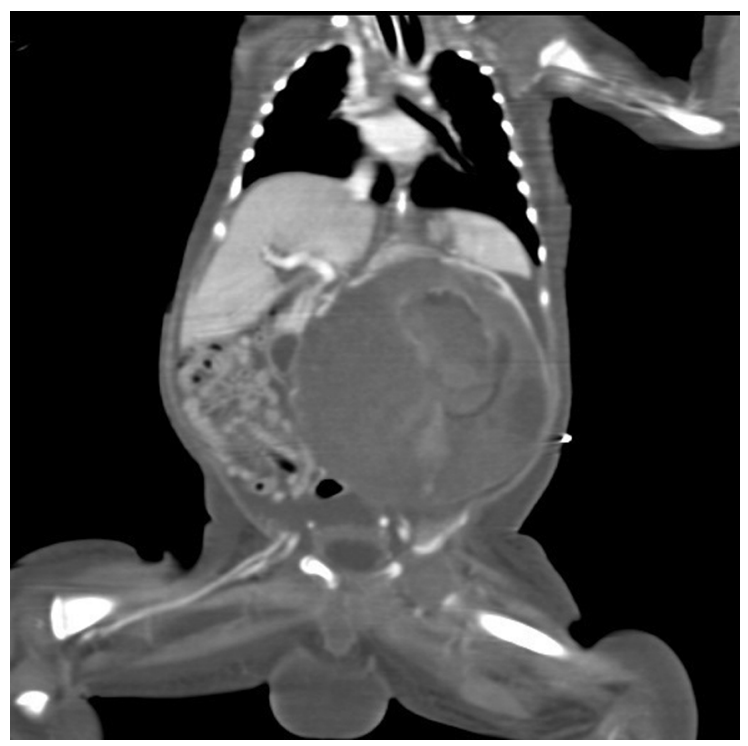

Fig 1. Computerized tomography imaging of the abdomen of hypertension has been expounded with the overproduction of renin from the tumor tissue or normal glomeruli with proliferated juxtaglomerular cells due to local ischemia. ${ }^{2,4}$ In our patient refractory hypertension proceeded to removal of the mass. We could not evaluate the value of renin before surgery due to the deterioration of his overall condition as we needed to get the patient to surgery rapidly. The difference in blood pressure measurements of upper and lower of limbs was significant due to the compression of the mass on the aorta. This made us think that the mechanism of the high blood pressure in CMN might be correlated with the compression that the mass made on the aorta.

Hypercalcemia has been reported $1.2 \%$ to $12 \%$ of CMN cases $(8,10)$. Consequence of production of parathyroid hormone, parathyroid-related peptide and prostoglandin E by tumor cells, have been associated with hypercalcemia in CMN (8). In our patient, the serum calcium was elevated to $13 \mathrm{mg} /$ $\mathrm{dl}$ and in clinical observation; it was detected at high levels until surgery. It was observed that the patient's calcium levels were normal in the follow-up of the patient in the first day after the operation. We could not evaluate parathyroid hormone levels due to immediate surgery demand of the patient before operation.

In previous studies it has been noted that hypercalcemia causes: the inhibition of active sodium chloride transport in the loop of Henle, redistribution of medullary blood flow, or disruption of water reabsorption in the collecting tubules. Polyuria has also been seen

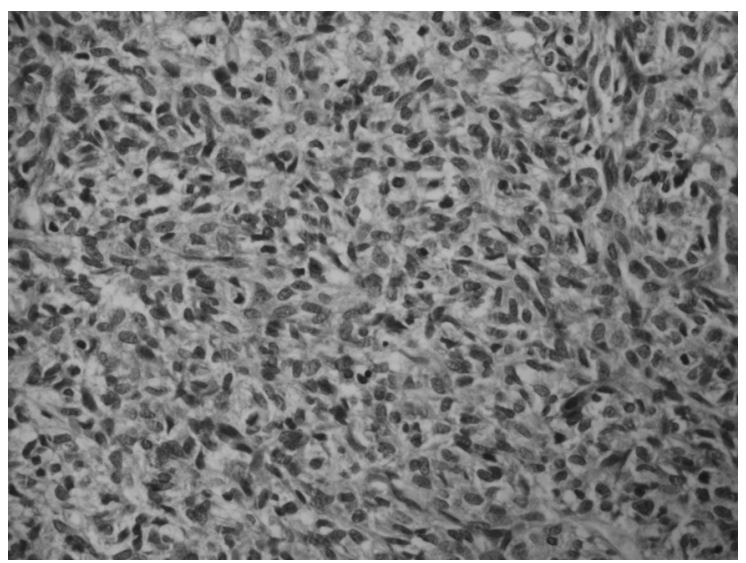

Fig 2. Fusiform and ovoid cells with high mitotic activity of the tumor 
in patients as an outcome of these mechanisms that occur due to hypercalcemia. ${ }^{8}$

Polyuria and hematuria have been reported in some cases of CMN. ${ }^{3,8}$ Hematuria did not occur in our patient but polyuria was reported during the preoperative period. Urine output increased to $12 \mathrm{ml} / \mathrm{kg}$ per hour. Polyuria decreased after nephrectomy.

The CMN has been pathologically classified into classic and cellular types by indication of microscopic appearance. ${ }^{11}$ The classic variant has been described predominantly solid, uncapsuled, with fusiform spindle cells, rare mitoses and absence of necrosis.5,10,11 Surgical resection has been reported as a definitive treatment for classical type of CMN as the tumor has low potential of recurrence and malignancy. 5,12 The cellular CMN has sarcomatosous appearance with high cellularity, mitosis, necrosis, hemorrhage and decreased cytoplasm with solid ovoid or fusiform spindle cells. On the basis of these pathological findings, cellular type of $\mathrm{CMN}$ tends to be more aggressive and patients with local recurrences or metastases were reported.6,10,12 In recent studies, it has been shown that both of the two tumor types are immunreactive to vimentin, desmin and smooth cell actin as a marker of fibroblastic differentiation. ${ }^{13,14}$ In our patient, a $10 \times 8 \times 3 \mathrm{~cm}$ solid mass on $3 \times 3 \times 3 \mathrm{~cm}$ cystic renal parenchyma had resection by surgery. Histologically, the tumor was characterized by fusiform and ovoid cells with high mitotic activity. The tumor cells were positive with vimentin and WT1 also negative with SMA, pancitoceratine, CD56 and CD99. In contrast to previous studies, desmin was not immunreactive for the tumor cells.

This case emphasizes the importance of an evaluation of $\mathrm{CMN}$ in cases with refractory neonatal hypertension and hypercalcemia. The identified significant hypertension in the upper extremities and the acute decline of blood pressure after the operation suggested the compression of the mass on the aorta as a hypertension mechanism of CMN. The surgical resection is the most common treatment for paraneoplastic symptoms of the tumor but pathologic findings are the main determinant of advanced follow-up and treatment of CMN.

\section{REFERENCES}

1. Bayindir P, Guillerman RP, Hicks MJ, Chintagumpala MM. Cellular mesoblastic nephroma (infantile renal fibrosarcoma): institutional review of the clinical, diagnostic imaging, and pathologic features of a distinctive neoplasm of infancy. Pediatr Radiol 2009; 39: 1066-1074.

2. Khashu M, Osiovich H, Sargent MA. Congenital mesoblastic nephroma presenting with neonatal hypertension. J Perinatol 2005; 25: 433-435.

3. Sheth MM, Cai G, Goodman TR. AIRP best cases in radiologic-pathologic correlation: congenital mesoblastic nephroma. Radiographics 2012; 32: 99-103.

4. Robertson-Bell T, Newberry DM, Jnah AJ, DeMeo SD. Congenital Mesoblastic Nephroma Presenting With Refractory Hypertension in a Premature Neonate: A Case Study. Neonatal Netw 2017; 36: 32-39.

5. Ahmed HU, Arya M, Levitt G, Duffy PG, Mushtaq I, Sebire NJ. Part I: Primary malignant non-Wilms' renal tumours in children. Lancet Oncol 2007; 8: 730-737.

6. Joshi VV, Kasznica J, Walters TR. Atypical mesoblastic nephroma. Pathologic characterization of a potentially aggressive variant of conventional congenital mesoblastic nephroma Arch Pathol Lab Med 1986; 110: 100-106.

7. Irsutti M, Puget C, Baunin C, Duga I, Sarramon MF, Guitard J. Mesoblastic nephroma: prenatal ultrasonographic and MRI features. Pediatr Radiol 2000; 30: 147-150.

8. Daskas N, Argyropoulou M, Pavlou M, Andronikou S. Congenital mesoblastic nephroma associated with polyhydramnios and hypercalcemia. Pediatr Nephrol 2002; 17: 187-189.

9. Haddad B, Haziza J, Touboul C, Abdellilah M, Uzan $S$, Paniel BJ. The congenital mesoblastic nephroma: a case report of prenatal diagnosis. Fetal Diagn Ther 1996; 11: 61-66.

10. Furtwaengler R, Reinhard H, Leuschner I, et al. Gesellschaft fur Pädiatrische Onkologie und Hämatologie (GPOH) Nephroblastoma Study Group. Mesoblastic nephroma--a report from the Gesellschaft fur Pädiatrische Onkologie und Hämatologie (GPOH). Cancer 2006; 106: 2275-2283.

11. Ordonrz G. Rosai J. Editors. Urinary tract in Rosai \& Ackerman's Surgical Pathology vol.1. 10th ed. St. Louis: Mosby: 2011 (Chapter 17)

12. Glick RD, Hicks MJ, Nuchtern JG, Wesson DE, Olutoye OO, Cass DL. Renal tumors in infants less than 6 months of age. J Pediatr Surg 2004; 39: 522-525. Review

13. Portugal R, Barroca H. Clear cell sarcoma, cellular mesoblastic nephroma and metanephric adenoma: cytological features and differential diagnosis with Wilms tumour. Cytopathology 2008; 19: 80-85.

14. Nadasdy T, Roth J, Johnson DL, Bane BL, Weinberg A, Verani R, Silva FG. Congenital mesoblastic nephroma: an immunohistochemical and lectin study. Hum Pathol 1993; 24: 413-419. 